\title{
O QUE PODE O TRABALHADOR NUM MODELO DE GESTÃO NEOLIBERAL? ${ }^{1}$
}

\author{
WHAT IS THE WORKER ENABLED TO IN A NEOLIBERAL MANAGEMENT MODEL? \\ ¿QUÉ ES LO QUE PUEDE EL TRABAJADOR EN UN MODELO DE GESTIÓN NEOLIBERAL?
}

\author{
Amanda Maria Marques Pimenta* \\ José Newton Garcia de Araújo*
}

\begin{abstract}
RESUMO
Este artigo discute os conceitos de sujeito e de trabalho, articulados à análise da atividade, no contexto de uma organização de economia mista. Questionam-se as possibilidades de o trabalhador ter acesso à condição de sujeito num modelo de gestão neoliberal. Partindo principalmente das contribuições teóricas da psicossociologia, o texto levanta as noções de pertencimento, autonomia e reconhecimento, pelas quais se discute a inter-relação entre saúde, trabalho e subjetividade. São também retomados alguns conceitos que balizam as atuais estratégias da ideologia gerencial. Os resultados, obtidos por entrevistas individuais e grupais, mostram os impasses na concretização do pertencimento, da autonomia e do reconhecimento, o que traz consequências negativas tanto para os trabalhadores quanto para a organização.
\end{abstract}

Palavras-chave: Sujeito. Trabalho. Pertencimento. Autonomia. Reconhecimento.

\begin{abstract}
This article discusses the concepts of subject and work, articulated to the analysis of the activity, in the context of a mixed economy organization. It questions the possibilities of the worker to have access to the condition of subject, in a model of neoliberal management. Starting mainly from the theoretical contributions of Psychosociology, the text raises the notions of belonging, autonomy and recognition, through which the interrelation between health, work and subjectivity is discussed. Some concepts that mark the current strategies of managerial ideology are also included in the discussion. The results obtained through individual and group interviews show the impasses in the achievement of belonging, autonomy and
\end{abstract}

\footnotetext{
Texto recebido em 6 de janeiro de 2016 e aprovado para publicação em 24 de setembro de 2016.

1 Este artigo é o resultado parcial da dissertação de mestrado da primeira autora, intitulada "O sujeito inserido no contexto da gestão de pessoas: o olhar dos trabalhadores em uma sociedade de economia mista”, defendida no Programa de Pós-Graduação da PUC Minas em 2015.

* Doutoranda no Programa de Pós-graduação em Psicologia da PUC Minas, psicóloga.

** Professor nos programas de Graduação e Pós-Graduação em Psicologia da PUC Minas, psicólogo.
} 
recognition, which has negative consequences for both workers and the organization.

Keywords: Subject. Work. Belonging. Autonomy. Recognition.

\section{RESUMEN}

Este artículo discute los conceptos de sujeto y de trabajo, articulados al análisis de la actividad, en el contexto de una organización de economía mixta. Se cuestionan las posibilidades de que el trabajador tenga acceso a la condición de sujeto, en un modelo de gestión neoliberal. A partir principalmente de las contribuciones teóricas de la Psicosociología, el texto presenta las nociones de pertenencia, autonomía y reconocimiento, a través de las cuales se discute la interrelación entre salud, trabajo y subjetividad. También se retoman algunos conceptos que sustentan las actuales estrategias de la ideología gerencial. Los resultados, obtenidos a través de entrevistas individuales y grupales, muestran los impasses en la concreción de la pertenencia, de la autonomía y del reconocimiento, lo que trae consecuencias negativas para los trabajadores y para la organización.

Palabras-clave: Sujeto. Trabajo. Pertenencia. Autonomía. Reconocimiento.

\section{INTRODUÇÃO}

$\mathrm{E}$

ste artigo procura discutir as relaçóes entre sujeito e trabalho, partindo da seguinte questão: pode o trabalhador ter acesso à efetiva condição de sujeito em uma empresa originalmente estatal e que, atualmente, passou ao regime de economia mista? Trata-se aqui de investigar a ambiguidade do modelo de gestão de uma organização que ainda guarda certas atribuições de instituição pública, mas que se pauta pelos padrões gerenciais de uma empresa privada, cujo objetivo maior é a maximização dos resultados financeiros, independentemente das consequências sofridas pelos trabalhadores ou pela própria instituição quanto à qualidade de seus serviços e produtos bem como à sua função social.

Segundo Calgaro (2010), o modelo gerencialista, prevalente nas atuais organizações de trabalho, é originário do neoliberalismo, inicialmente implantado pelos governos norte-americano e inglês, em meados da década de 1980. Essa forma de gestão, hoje mundializada, prega a economia de mercado como solução para a crise capitalista presente na Pós-Modernidade. Dentro desse contexto, resultados financeiros, lucro e eficiência empresarial passaram a figurar como objetivo principal das práticas de gestão, em detrimento da saúde, do bem-estar e da qualidade de vida física e psicossocial dos trabalhadores. 
É nesse contexto que questionamos se tal modelo de organização pode inviabilizar a posição do trabalhador como sujeito, já que ele é designado a proceder como um operador passivo, tornando-se apenas um instrumento, um recurso que integra o modelo de gestão marcado pela primazia do lucro. Tal reificação implica, para o trabalhador, uma perda de seu lugar como sujeito responsável pelo funcionamento da empresa, o que resulta em perda de sentido do próprio trabalho. Gaulejac $(2007$, p. 27) observa que o gerenciamento é uma "tecnologia de poder, entre o capital e o trabalho, cuja finalidade é obter a adesão dos empregados às exigências da empresa e de seus acionistas". Segundo o autor, esse poder gerencialista é uma ideologia que, sob uma aparência objetiva e pragmática, "traduz as atividades humanas apenas como indicadores de desempenhos, e esses desempenhos em custos ou em benefícios" (Gaulejac, 2007, p. 36).

A organização em questão, sendo uma empresa público-privada de grande porte do setor energético, dado o seu grande número de empregados e o volume de negócios, utiliza frequentemente metodologias e ferramentas, ditas avançadas, na gestão de pessoas. No entanto suas práticas, supostamente inovadoras, não têm produzido o efeito ou o retorno prometido, em relação ao sentimento de pertencimento e de satisfação, por parte de seus trabalhadores, como atestam os dados colhidos nesta pesquisa. Esta resultou de um trabalho de escuta desses trabalhadores, por meio de entrevistas semiestruturadas, individuais e grupais. Nosso objetivo foi o de investigar as possibilidades de eles se tornarem ou não sujeitos, na apropriação de suas atividades de trabalho, como inseridos num contexto de gestão baseado no modelo do capitalismo financeiro.

Nos dados aqui discutidos, buscou-se delimitar os conceitos de sujeito e trabalho, com base em contribuições teóricas da psicossociologia francesa e das clínicas do trabalho, entre outras, tendo como pano de fundo as noções de pertencimento, autonomia e reconhecimento, aspectos que consideramos fundamentais para a estruturação da relação entre trabalho e subjetividade.

\section{PROCEDIMENTOS METODOLÓGICOS}

A pesquisa de campo foi realizada, na organização em estudo, com dois grupos de funcionários de carreira técnica, sendo o primeiro com os que desempenham funçôes gerenciais (que chamaremos de gerentes) e o segundo com os que exercem funções de nível médio e superior (que chamaremos de técnicos). Com os primeiros, foram realizadas nove entrevistas individuais semiestruturadas e, com os segundos, entrevistas em grupos, à maneira dos grupos focais que, segundo Kind (2004, p. 125), "utilizam a interação grupal para produzir dados e insights 
que seriam dificilmente conseguidos fora do grupo". A escuta dos sujeitos que compõem esses dois grupos, na função gerencial e na carreira técnica, evidenciou suas diferenças de percepção, com base na atuação ou não na função de liderança.

Procedeu-se a uma análise de conteúdo dos dados levantados. Essa técnica, segundo Desprairies e Lévy (2005), tem como objetivo tornar os discursos mais inteligíveis e, portanto, mais acessíveis a diferentes leitores. Nesse sentido, há a passagem de um discurso singular, apropriado à utilização privada, para um discurso partilhável, inteligível por outros, podendo servir a finalidades coletivas, no plano teórico e nas práticas de intervenção.

A análise de conteúdo das entrevistas foi balizada no eixo "O sujeito inserido no contexto da gestão neoliberal", que contempla as seguintes categorias: "a possibilidade de ser sujeito"; "o sentimento de pertencimento, em relação à organização"; "o poder e a autonomia do trabalhador nesse modelo de gestão"; e "o reconhecimento do sujeito trabalhador, nesse mesmo contexto".

\section{O SUJEITO INSERIDO NO CONTEXTO DA GESTÃO NEOLIBERAL}

\subsection{A possibilidade de ser sujeito}

A reflexão acerca do sujeito, nesse contexto, parte das considerações de Enriquez (2006), segundo as quais, com base na psicanálise, sabe-se que o homem moderno é dotado de uma atividade psíquica intensa e contínua, que engloba o jogo das pulsões, dos desejos e fantasias, além dos processos de recalque, de idealização e projeção, aspectos que animam tanto a vida dos indivíduos como da sociedade. $\mathrm{O}$ autor considera que o sujeito psíquico reconhece suas contradições e conflitos, pois percebe que não é totalmente senhor de sua própria casa, já que é movido também pelo inconsciente, submetido à vacilação e ao medo do despedaçamento. No entanto, ele é capaz de fazer de suas falhas o trampolim para chegar à posição de ser humano e social.

Com base nessas premissas, a possibilidade de ser sujeito, no contexto de trabalho, pressupõe um espaço institucional que permita ao trabalhador falar e agir, no sentido de sua participação efetiva na empresa, com reflexos nos processos cotidianos de produção de ideias, no enfrentamento de conflitos e na avaliação das políticas de gestão que definem os destinos da organização. $\mathrm{O}$ que se deduz, porém, do relato dos gerentes e técnicos é uma série de impedimentos à construção desse espaço de participação. Sabemos que a noção de "atividade impedida" é um dos pilares da teoria de Clot (2006), relativa ao que ele denomina 
"real da atividade", outra noção que nos permite ir além da análise daquilo que efetivamente se faz, pois incorpora as vivências internas e mesmo as experiências não visíveis do sujeito, no resultado de seu trabalho. O autor pretende, assim, explicitar a função psicológica da atividade de trabalho.

Os dados colhidos na pesquisa evidenciaram, por exemplo, que os impedimentos à participação dos envolvidos começam pelo não treinamento específico para determinadas funções e processos de trabalho.

A coisa está complicada, nesse sentido. É cobrado isso da gente, a gente procura fazer, mas também não tem um preparo, não recebe um preparo pra fazer. É cobrado, simplesmente "você se vira e faça, você não fazia essa função, sua função é técnica, mas você tem que fazer isso, isso, isso e isso, a partir de agora (Técnico).

Os próprios gerentes, muitas vezes, têm clareza dessa falta de treinamento, identificando essa demanda dos subordinados:

Necessidade do apoio, chegar junto, defender a equipe, entender as dificuldades, tentar solucionar juntos as dificuldades. Eu percebo isso da parte deles o tempo inteiro. Eu sou interrompida aqui, com dúvidas sobre posicionamento, com dúvidas pedindo orientação. Então eu sinto que eu preciso dar essa orientação e essa atenção. Então eu sei pela demanda dele (Gerente).

Apesar de perceber tal demanda, os gerentes costumam reproduzir uma posição de controle, no qual a subjetividade é colocada a serviço da visão funcionalista da gestão, que visa ao resultado a qualquer custo.

As pessoas estão perdendo um pouquinho [...] você ter gestão e você ter controle, e, por não saber, algumas pessoas estão querendo controlar tudo. E um dos piores modelos de gestão que tem é você controlar, você controla, controla, controla, mas, na verdade, você não tá fazendo gestão de nada, você é um excelente controlador, controlador de voo mesmo [...] Mas você não influencia naquela trajetória (Gerente).

Asubjetividade, nesse caso, entra em cena como um aspecto do próprio controle. Enriquez (1996) lembra que, nas novas tecnologias gerenciais, as empresas apregoam a inovação, contanto que seja uma inovação vigiada; a participação, mas esta deve ser uma participação controlada; elas também anunciam a liberdade, mas praticam o controle. Nesse contexto, cada empregado é visto a partir de um padrão, e aqueles que se diferenciam um pouco são considerados desviantes. Além disso, constrói-se uma psicologização dos problemas, sempre abordados no âmbito individual. Tudo é uma questão de autoconhecimento ou de estar fora de determinado padrão. A consequência adoecedora de certas 
condutas gerenciais, consideradas imutáveis, é negligenciada. Nesse sentido, o ônus do fracasso permanece sobre o indivíduo e não sobre os contextos internos e externos à organização. É o que reflete a fala de um entrevistado:

Tem coisa que é no plano individual, tem coisa que é quase que um a um mesmo [...] Algumas pessoas encaram com facilidade, outras se retraem completamente. Dependendo do grau de maturidade de cada um [...] Não sei [...] (Gerente).

A tentativa de submeter os empregados a um determinado padrão passa-lhes a percepção de estarem segregados, pois as condutas e medidas gerenciais são impostas, sem que eles possam delas participar:

E ele foi segregado durante o processo todo, e sendo cobrado por produtividade. E ele correspondia, porque ele era uma pessoa de índole boa [...] Ele não parou de trabalhar, porque foi tirado de lá. A família dele ficou longe. Ele foi transferido, mas ele continuou trabalhando normalmente, e a empresa não tomou conta dessa [...] $\mathrm{O}$ gerente, que isso aí é uma coisa gerencial, não tomou conta do ser humano nem sequer encaixou o indivíduo (Técnico).

"Mas o que pega, às vezes, é isso, muita gente preparada, sem ver uma luz, um caminho pra conseguir se reposicionar na empresa, conforme a qualificação dele" (Técnico).

Essa segregação resulta na perda de confiança na organização, pois ela não oferece possibilidades de satisfação. Gaulejac (2011) afirma que o conceito de organização compreende um sistema sociopsíquico que favorece a articulação entre, de um lado, procedimentos, normas, dispositivos funcionais e ferramentas de gestão e, de outro, processos psíquicos como introjeção, projeção, idealização e sublimação, permitindo canalizar a energia libidinal, transformando-a em energia produtiva, por meio do estabelecimento de um contrato narcísico entre empregado e empresa. A tentativa de controle e submissão do trabalhador não tem o sucesso desejado. Ao contrário, tem consequências negativas, pois ela não consegue o engajamento dos empregados e a mobilização de sua capacidade de trabalho. Vejamos o que diz um participante:

O pessoal de campo, que é o pessoal que produz, ele tem uma visão diferente do grupo que está aqui em geral e parece que está havendo uma ruptura de confiança. A pessoa já não confia mais na empresa. Eu nunca vi, desde que eu entrei, eu tenho nove anos de empresa [...] hoje é o pior momento que eu vejo de perceber as pessoas (técnico).

Aqui acima evocamos a noção de contrato narcísico entre o trabalhador e a empresa. A literatura relativa às organizações evoca também a noção, a nosso ver 
pouco consistente, de "contrato psicológico de trabalho" (Rousseau, 1995), que supõe uma expectativa implícita, não formal, de reciprocidades de prestações (comprometimento) e contraprestações (gratificações materiais e simbólicas) entre as duas partes. Neste estudo, parece que esse suposto contrato é rompido pela própria empresa, cujas práticas gerenciais deixam de levar em conta a subjetividade de cada trabalhador, retirando-lhe os espaços de participação nos processos de trabalho e na gestão.

Outro aspecto negativo do controle excessivo e ineficaz é o aumento da competitividade interna, que contribui para a enfraquecimento do coletivo de trabalho. Isso aparece no discurso dos gerentes, ao comparar os empregados que atingem ou não o padrão de desempenho desejado, gerando uma disputa entre eles, para que alcancem o padrão idealizado de produção. A corrida para atingir metas impede, inclusive, que cada indivíduo tenha tempo de pensar suas escolhas e desenvolver seu próprio estilo de trabalho. Em síntese, a competitividade imposta leva à perda do laço social, como se a adesão ao coletivo colocasse em risco a própria sobrevivência. Enriquez (1991) lembra que, na constituição desse laço, as relações de força dão lugar a relações de aliança e solidariedade. No caso de nossa investigação, estas estavam impedidas pelo imperativo da disputa entre os pares:

Sempre a comparação, por exemplo, nós dois, nós dois trabalhamos aqui, temos a mesma função, qualquer coisa que tiver a mais pra você é olhado o que está acontecendo com o outro, não o olhar pra si mesmo. E eu estou sentado numa cadeira, por exemplo, que tem um entorno em volta dela, um outro gerente está numa cadeira que tem um outro entorno. Então, penso assim [...] Tudo o que for comum tem que ser comum. Agora, existem algumas coisas que não são comuns e não podem ser comuns. É essa comparação que, às vezes, cria uma ansiedade muito grande nas pessoas (Gerente).

Esse estilo de gestão inviabiliza que os trabalhadores assumam a posição de sujeito, o que não é sem consequências, tanto do ponto de vista individual quanto institucional. Os gerentes e os empregados de carreira técnica têm consciência da necessidade de mudança, mas esta é vista sobretudo como responsabilidade do indivíduo, não da gerência. A esse respeito, Enriquez (2001, p. 28) lembra que todo indivíduo nasce em uma sociedade que instaurou, consciente e inconscientemente, uma cultura. "Em outras palavras, é impossível analisar a conduta de um indivíduo sem referi-la à conduta dos outros para com ele, conduta essa estruturada social e culturalmente". No plano microssociológico, lembremos a propalada "cultura da empresa" ou "cultura organizacional". Daí o equívoco de se analisar a conduta individual sem considerarmos sua dimensão de heteronomia. 
Cabe ressaltar ainda, por outro lado, que o discurso gerencial, mesmo quando autoritário, não consegue reinar totalmente sobre o consciente e o inconsciente do sujeito, provocando fenômenos de resistência, a médio ou longo prazo. A esse respeito, Canguilhem (2001, p. 116) observa que a resistência do trabalhador ao que lhe é imposto do exterior equivale a reaçôes de defesa biológica e social e, nos dois casos, devem ser compreendidas como reações de saúde.

\section{2 $\mathrm{O}$ sentimento de pertencimento em relação à organização}

A análise das entrevistas aqui discutidas nos permite explorar o tema da identificação (ou sua ausência) à organização, o que contribui para a sustentação do vínculo social e do sentimento de pertencimento. Rouchy (2001) examina as modalidades por meio das quais se efetua a passagem do intrapsíquico ao psicossocial, da identificação à identidade. Aqui o grupo ocupa a função de espaço transicional, sendo um campo de experiência intermediária entre a vida interior e a realidade exterior, em que se opera a metabolização das realidades do dentro e do fora.

Cabe lembrar também, segundo Chanlat (2011), que o espaço organizacional constitui um lugar dividido e imposto, do qual os trabalhadores procuram se apropriar, independentemente de sua posição e a despeito de suas dificuldades. Trata-se de um lugar rico simbolicamente, um teatro de interações, um lugar de enraizamento. Nesse sentido, o espaço fixa a identidade pessoal e social, oferece posições de referência e é fonte de carga afetiva e emocional.

Para os participantes de ambos os grupos, o sentimento de pertencimento se encontra fragilizado, pois o vínculo com a organização não produz mais satisfação.

Vem piorando, na minha opinião, vem piorando. Ah! Eu associo isso tudo a essa [...] A esse processo que está levando os empregados [...] Eu chamo de desencanto para com a empresa. Porque a empresa realmente encantava. Encantava! As pessoas construíram a vida aí (Gerente).

Antigamente, a gente vestia uma camisa [...] Eu era leiturista [...] Eu achava que eu ficava mais importante de uniforme do que de roupa normal... Sério mesmo, uai! [...] Tinha esse sentimento. Eu entrava nos lugares aí com a camisa da empresa, o povo me respeitava. Hoje, você entra, eles não estão nem aí [...] E a pessoa também não tem mais aquele orgulho de colocar um uniforme e ir pra rua com ele, não! Está ali pra cumprir horário e ir embora correndo (Técnico).

Quando o contrato imaginário (mais que simplesmente narcísico ou psicológico) e o vínculo do sujeito com a organização estão enfraquecidos, 
abrem-se as portas do sofrimento, relativa tanto ao cotidiano do trabalho quanto aos projetos de carreira na empresa. A análise dos relatos deixa evidentes alguns aspectos dessa fragilização do pertencimento. Os empregados de carreira técnica mencionam, por exemplo, que não é possível se vincular àquilo que não tem sentido ou significado.

E aí fica difícil você criar vínculo com número. Vínculo é uma coisa que é afeto, afeto de afetar, não é de sentimento, não, é de afetar, a pessoa tem que estar afetada. Como que se afeta uma pessoa? Entregando um número pra ela, um papelzinho assim pra ela assinar um contrato de meta? Ela vai engavetar aquele negócio. A pessoa, pra ter sentido, ela tem que ter um vínculo com aquilo. Criar vínculo, você tem que criar conversando, explicando, contando pra pessoa como é que você chegou naquele número ali, porque que esse número precisa ser assim [...] (Técnico).

O relato acima mostra que os trabalhadores de carreira técnica têm uma demanda explícita de participação nos processos de trabalho, o que inclui uma efetiva presença na formulação de políticas ou procedimentos, levando à reconstrução do vínculo com a organização. Um participante evoca mesmo a noção da legitimidade, referindo-se ao trabalho construído coletivamente:

Eu tenho colegas quem vêm do Triângulo, colegas que vêm do Norte [...] Culturas diferentes, pensamentos diferentes, todo mundo opera rede [...] Fazia a mesma coisa, mas de formas diferentes. Então, tem três anos que já estamos assim, trabalhando procedimento, escrevo muitas instruções, mas escrever instrução é o mais simples. Tem que ter legitimidade o que ele falou, participação das pessoas, pra ter aceitação. Se não tiver legitimidade, não adianta entregar o papel porque ninguém cumpre (Técnico).

No entanto, a organização parece negligenciar essa demanda de participação, visto que intensifica os mecanismos de controle:

A gente volta lá naquele excesso de controle. Muitas das vezes, a preocupação não está tanto em processo e muito em controle [...] hoje, as empresas, elas estão modernizando cada vez mais, automatizando cada vez mais, tentando ganhar uma agilidade muito grande $[\ldots]$ só que, como ela está tendendo muito pra controle, controle, controle, a parte das pessoas eu acho que está um pouquinho prejudicada. Então, quando você me perguntou o que que pode ser feito pra melhorar a gestão de pessoas [...] Tem que deixar o controle de lado (Gerente).

Perguntamo-nos aqui se haveria um deslizamento entre as noçóes de controle e de pressão exercida sobre o sujeito, no sentido da intensificação do trabalho. No entanto há gerentes que, tendo internalizado a ideologia gerencial, parecem minimizar a ideia de pressão, ao entenderem que, nas novas tecnologias de gestão, o que falta ao trabalhador é a capacidade de adaptação: 
Pressão eu não sinto, mas eu sinto que uma pessoa que não tem essa flexibilidade, essa capacidade de mudança, ela sofre [...] Ela vai ficar com aquele saudosismo de imaginar que "sempre deu certo de um jeito, porque que eu vou mudar isso agora?" [...] Porque a gente precisa é de pessoas que tenham essa capacidade de adaptação, de inovar, de ver que: "Oh, a gente tem uma ideia diferente pra gente fazer um trabalho melhor" (Gerente).

Essa exigência de adaptação, segundo Enriquez (2006), pode ser mais uma estratégia de levar os trabalhadores a se identificar com as organizações das quais fazem parte, a idealizá-las, colocando os valores organizacionais em lugar dos seus próprios valores, transformando-se em instrumentos submissos e dóceis, o que pode conduzir a novas modalidades de alienação e, por consequência, de adoecimento mental. Além disso, a gestão costuma atribuir a capacidade de adaptação apenas a um problema individual, responsabilizando ou culpabilizando o trabalhador diante dos problemas organizacionais. Isso leva a um estado permanente de estresse e mesmo de adoecimento, pois é o sujeito que deve "adaptar-se" para mostrar sua excelência, ao risco de ser considerado inútil, de ficar isolado ou ser excluído, apesar dos esforços despendidos. Isso fica evidente nas falas dos participantes:

Tudo que nós conversamos aqui, tudo isso vai somatizando. É o controle que está muito, é a comparação minha com fulano. Então, ou seja, você gasta muita energia com tudo isso que está acontecendo (Gerente).

Eu estou falando especificamente da minha área, eu e as pessoas que estão lá comigo. É uma pressão muito forte, acaba que as pessoas adoecem [...] Eu nunca tive problema de pressão alta e comecei a ter de uma hora pra outra. Quando eu fui fazer o exame, que é aquele mapa, que você fica 24 horas, a pressão só estava alterando dentro da empresa. E, graças a Deus, a sequência não foi tomar medicamento, não chegou nesse nível. Mas foi detectado que é aqui dentro (Técnico).

\subsection{O poder e a autonomia do trabalhador, nesse modelo de gestão}

Já evocamos acima que toda conduta individual é, em parte, heterodeterminada. Castoriadis, citado por Enriquez (2001), para quem: "Todo indivíduo é fundamentalmente heterônimo, isto é, ele só existe e só pode funcionar no interior de um social dado, de uma cultura particular que desenvolve suas "significações imaginárias" específicas e que lhe dita, em parte, sua conduta" (p. 28).

Em contraposição, o autor afirma que todo indivíduo só é parcialmente heterônimo. Ou que ele "é um desvio em relação a todos os outros, na medida em que sua psique se estrutura progressivamente, apoiando-se nas funções corporais, em pessoas e grupos diferentes" (p. 29). Assim, todo indivíduo "está 
sempre em condiçóes de demonstrar, como evocava Freud, uma parcela de originalidade e de autonomia" (p. 29), e pode desempenhar um importante papel nas transformações sociais.

Neste estudo, quando falamos de autonomia, julgamos essencial levar em conta as considerações acima. Somente então poderemos desenvolver as discussões que se seguem, a partir, por exemplo, dos conflitos entre o poder hierárquico e os níveis inferiores da empresa em questão.

Segundo alguns participantes, a estrutura formal da empresa se tornou menos hierarquizada nos últimos anos. Para o grupo dos gerentes, isso poderia aumentar a liberdade e a autonomia dos trabalhadores. No entanto eles reconhecem a prevalência do poder hierárquico em muitas situaçôes. Quanto aos técnicos, estes têm uma visão mais crítica ainda em relação à suposta redução da hierarquia, afirmando que ela não se faz efetiva na prática.

Então, [...] não sei se foi uma época de modismo, que falou "olha, vamos achatar a empresa, vamos empoderar os empregados”. Só que o empoderar é dar mais autonomia, mas talvez não [ocorreu] com o reconhecimento necessário. Então, talvez essa falta de reconhecimento formal seja por isso (Técnico).

A pretendida diminuição da hierarquia remete à tendência gerencial de substituir o controle e a dominação explícita pela adoção de formas sutis que veiculam, justamente, a ideia ilusória de autonomia. Nesse sentido, Gaulejac (2007) considera que, ao contrário do poder disciplinar anteriormente instituído para mobilizar os corpos, tornando-os úteis, dóceis e produtivos, o poder gerencialista produz uma dominação da psique, colocando-a a serviço da produção. Esse poder utiliza um conjunto de técnicas que captam desejos e angústias para direcioná-los em proveito da empresa, transformando a energia libidinal em força de trabalho. Desse modo, os indivíduos são presos a um sistema paradoxal que os leva a uma submissão livremente consentida.

A autonomia forjada pela diminuição da rigidez das regras é questionada por ambos os grupos. Os gerentes sentem que, efetivamente, não têm poder de decisão. "Tem coisas que você tem uma ação gerencial, que você consegue fazer, você consegue melhorar essa questão; tem outras que você não consegue, extrapola a atuação gerencial no dia a dia" (Gerente).

Observe-se que a ausência de autonomia, sempre relativa, não advém de uma falta de capacidade do sujeito, mas do próprio modelo de gestão, que retira essa possibilidade, inclusive de quem está em posição de liderança, como os gerentes. Também afirmando que a heteronomia é anterior à autonomia, Ollivier (2005) comenta que "um indivíduo é considerado livre e autônomo desde que pertença a um corpo social que adquiriu as condiçōes de sua autonomia". No caso dos 
participantes desta pesquisa, a própria experiência de pertencimento ao corpo social da empresa ou a um coletivo de trabalho parece comprometida.

Além disso, o sentimento de dependência se liga à percepção dos entraves próprios aos trâmites burocráticos, marcados por normas e regras nem sempre úteis ao funcionamento da organização:

Mas a mudança, ela foi muito drástica. Excluiu muita coisa e retirou bastante autonomia. Ela, de certa forma, deu autonomia informal, mas hoje tem muita limitação e burocracia. Na verdade, a empresa ainda não conseguiu se desvencilhar da burocracia (Técnico).

O fenômeno burocrático decorre inclusive no fato de o sujeito ocupar uma posição designada na hierarquia, como o próprio cargo de gerente: "Então você, como gerente, você tem algumas obrigaçôes, acaba que você tem uma imagem [...] Botou o seu nome de gerente, não interessa se você tem autoridade ou não, tem poder ou não [...] As pessoas vão ter que te reconhecer como tal" (Gerente).

O poder burocrático, segundo Enriquez e Michel (2005), faz-se evidente na estrutura da organização. A divisão do trabalho afeta não somente os trabalhadores na base da hierarquia, mas também aqueles que ocupam a função de dirigentes. Cada qual vai ter um posto e vai se comportar segundo algumas prescrições. Define-se então uma multiplicidade de micropoderes formais, impessoais, funcionais e limitados. A obediência é devida à função e não à pessoa que a ocupa, ao mesmo tempo em que o poder ou a capacidade decisória são limitados pelas regras e procedimentos, que têm força de lei.

A prevalência do controle, presente nas falas dos participantes, permite-nos supor que, na aparente redução da hierarquia, predominam a submissão e a obediência a normas às vezes abstratas e sem sentido, que impedem o movimento de autonomia. Assim, o poder de decisão de cada trabalhador fica relativizado, sua competência e seu conhecimento do próprio trabalho ficam à margem, deixam de ser legitimados ou considerados.

\section{4 $\mathrm{O}$ reconhecimento do sujeito trabalhador nesse mesmo contexto}

O reconhecimento pressupõe um olhar e uma validação do outro, que pode vir da própria organização ou das demais pessoas que participam de seu funcionamento cotidiano. Segundo Lhuilier (2005), ele pressupõe uma relação simbólica, visto que a inscrição em um grupo é a condição para a validação das próprias práticas. $\mathrm{O}$ reconhecimento é, ao mesmo tempo social, pessoal e institucional. $\mathrm{Na}$ organização aqui estudada, o relato dos empregados de carreira 
técnica mostra que ele pouco ocorre, uma vez que certas contribuições ou funções não estão formalizadas na estrutura organizacional.

Então, você tem que dar resultados, de acordo com as diretrizes que foram estabelecidas, e não pedir nada por isso [...] Mas a dificuldade que a empresa tem pra reconhecer a pessoa, esse talento que assumiu as responsabilidades, aderiu a isso espontaneamente [...] Porque quando você coordena [...] Você não vai aparecer em nada, em documento nenhum, porque a empresa não reconhece a sua coordenação. Então, você é um sujeito oculto. Claro, você tem lá [...] O gerente reconhece, o superintendente, o processo te reconhece, você fica visível lá, mas formalmente oculto (técnico).

Do ponto de vista institucional, o reconhecimento pressupóe, evidentemente, salários dignos e promoçóes, como suportes necessários a um sujeito que tem necessidades simbólicas, psicológicas e materiais. O reconhecimento não pode, pois, restringir-se a esse aspecto. Mas quando ele falta, há uma diminuição do investimento dos trabalhadores, traduzido na fala dos participantes como falta de motivação. "Falta de um reconhecimento de repente até individual, no dia a dia, de alguma coisa menorzinha, que não esteja vinculada com dinheiro" (Gerente).

E aí você vai jogando as pessoas pra baixo e a motivação é diretamente proporcional ao desempenho. Quem não está motivado entrega o mínimo e olhe lá [...] porque você não tem retorno pelo que você faz de diferente. Quando você é diferencial, você não percebe um diferencial na política da empresa (técnico).

Essa diminuição do investimento, segundo Lhuilier (2005), está relacionada à gestão que deixa de valorizar ou mesmo marginaliza o trabalhador. É somente a partir da relação a um terceiro que cada qual pode ter a certeza da pertinência, da qualidade e da validade daquilo que realiza. Esse olhar é múltiplo, no interior da instituição, ele corresponde a expectativas distintas do sujeito. Segundo os gerentes entrevistados, no entanto, mesmo o reconhecimento financeiro está minguando, pois a gestão não disponibiliza recursos suficientes nem para as recomposições salariais ou promoções.

Na medida de um possível que é um possível cada vez menos, há um reconhecimento através desse tal processo que eu te falei, da avaliação de desempenho, em que há uma distribuição de dinheiro anual, mas é pouco [...] É pouco (Gerente).

Quanto aos técnicos, a demanda de reconhecimento ultrapassa o plano financeiro. Eles valorizam os aspectos institucionais, tais como as promoçôes, embora estas sejam, às vezes, assimiladas ao discurso da meritocracia, cujos ingredientes ideológicos não são questionados. Essa noção é antes associada a habilidades, conhecimentos e competências que tornam o sujeito capacitado a atuações diferenciadas. Nesse caso, 
diríamos que, quando a gestão busca apenas resultados, ela não se volta para o trabalho em si, relativo ao desenvolvimento pessoal e ao fazer criativo do empregado. A esse respeito, vale lembrar as observaçōes de Schwartz (2011, p. 134), para quem "a atividade de trabalho, no essencial, não se vê. Somente são apreendidos, de maneira relativamente acessível, seus resultados, seus meios: produtos, bens, serviços [...] meios e produtos visíveis, quantificáveis". Em outras palavras: a atividade de trabalho em si, ligada à construção da subjetividade, ao desenvolvimento das capacidades individuais, é invisível, ela comparece como uma usinagem "em penumbra", é aquilo que é tecido ou construído em silêncio, que se opera entre a norma e o que é renormalizado, entre o trabalho prescrito e o trabalho real. "Muito bom o seu trabalho. Se você continuar assim você vai ser premiado [...] Mas ela não se torna uma realidade na empresa. Você não dá crédito a quem merece" (Técnico).

Aqui se subentende ainda a possibilidade de o sujeito escolher as funções ou o local específico onde deseja trabalhar, visando ao desenvolvimento da carreira. Mas isso só ocorre por meio do jogo de micropoderes, não por uma política definida da empresa:

Pessoas que são boas de serviço [...] desenvolvendo um trabalho legal. Essa pessoa não consegue sair pra encarreirar em outra área. Ela é punida porque ela é boa de serviço. Em contrapartida, os empregados rebeldes, que brigam, eles são tratados na palma da mão, e eu ouvi os gerentes oferecendo: "Escolhe pra onde você quer ir que eu vou te liberar [...]" (Técnico).

Esta fala reflete o que Gaulejac (2007, p. 37) afirma a respeito da gestão gerencialista, ou seja, que ele é uma mistura de regras racionais, de instrumentos e técnicas objetivas de avaliação, "mas também de regras irracionais, de prescrições irrealistas, de painéis de bordo inaplicáveis e de julgamentos arbitrários".

\section{CONSIDERAÇÕES FINAIS}

O livro de Gaulejac (2007), aqui citado, tem como título original "A sociedade doente da gestão" (La société malade de la gestion), embora sua tradução em português seja "Gestão como doença social". A pesquisa apresentada parcialmente nesse texto reflete bem essa realidade "doentia" que remete, numa relação de recíproca influência, às estruturas da gestão e da sociedade. Com efeito, a gestão constitui, sob a capa do pragmatismo, uma ideologia que legitima a busca insensata do rendimento financeiro, dentro de uma lógica que salta os muros da empresa e invade todos os recantos da sociedade (família, escola, esporte, política, serviços públicos, vida privada) que se torna um vasto mercado competitivo.

Este estudo nos mostra o gerencialismo como uma expressão de poder, destinada a obrigar a adesão do trabalhador às políticas da empresa, voltadas 
prioritariamente para o rendimento. Gaulejac (2007, p. 27) comenta que a gestão, como ideologia, "legitima uma abordagem instrumental, utilitarista e contábil das relações entre o homem e a sociedade". Diríamos, então, que esse contexto aponta para a "intensificação da insignificância", segundo uma expressão de Castoriadis (1996), para quem uma verdadeira democracia deve questionar suas instituições e suas significações, pois ela sujeita ao risco contínuo da mortalidade virtual de toda significação instituída. No caso, vemos que o trabalho está perdendo sua significação de instituição que produz cultura, no sentido freudiano de civilização (Lhuilier, 2017), trabalho como instituição que preside ou dá sustentação aos processos de subjetivação e de fortalecimento dos laços sociais.

Vimos também que o trabalho em si deixa de ser objeto de análise, como fator de transformação do mundo e do sujeito, pois o que conta, como já dissemos, é o seu produto rentável. Enfim, o modelo perverso de gestão neoliberal somente vê o trabalho por meio de indicadores de desempenho, ali onde o sujeito humano e sua atividade não passam de um recurso. Este cenário desemboca não só na crise das identidades no trabalho, mas nas formas diversas de adoecimento físico e mental. A ética está comprometida nesse modelo, no qual o assédio moral se torna uma prática inerente à própria gestão. Por isso, conforme o testemunho dos participantes deste estudo, ficam evidentes o sentimento de pertencimento apenas precário à organização, aliado à perda de autonomia e de reconhecimento

Finalmente, no plano macrossocial, a sentido da política se rende aos interesses da economia neoliberal que faz das relaçóes humanas um terreno de competitividade, de produção da violência e da vulnerabilidade social. Nesse sentido, nada mais atual que as considerações de Gaulejac (2007, p. 308), para quem a política passa a ser conduzida como um negócio a ser gerenciado, dentro dos padrões do puro utilitarismo: "Vemos até homens políticos preconizarem gerenciar a sociedade como uma empresa, para torná-la mais eficaz e mais rentável". Eis aí um funesto cenário que explicita como as organizações do trabalho e as sociedades democráticas estão fragilizadas em suas instituiçốes e, finalmente, em sua própria razão de ser, de sua significação. 


\section{REFERENCIAS}

Calgaro, J. C. C. (2010). Ensaio sobre os efeitos perversos do gerencialismo no sofrimento do trabalhador: contribuiçôes da sociologia clínica e da teoria crítica. In A. M. Mendes, A. R. C. Merlo, C. F. Morrone \& E. P. Facas (Orgs.), Psicodinâmica e clínica do trabalho: temas, interfaces e casos brasileiros. (pp. 179-192). Curitiba: Juruá.

Canguilhem, G. (2001). Meio e normas do homem no trabalho. Pro-posições, 12(2-3), 109-121.

Castoriadis, C. (1996). La montée de l'insignifiance: carrefour du labyrinthe IV. Paris: Seuil.

Chanlat, J. F. (2011). O desafio social da gestão: a contribuição das Ciências Sociais. In P. Bendassolli \& L. A. P. Soboll (Orgs.), Clinicas do trabalho: novas perspectivas para a compreensão do trabalho na atualidade. (pp. 110-131). São Paulo: Atlas.

Clot, Y. (2006). Função psicológica do trabalho. Petrópolis: Vozes.

Desprairies, F. G. \& Lévy, A. (2005). Análise de discurso. In E. Enriquez, A. Lévy \& J. B. Michel (Orgs.), Dicionário de psicossociologia. (pp. 232-241). Lisboa: Climepsi.

Enriquez, E. (1991). Da horda ao Estado: psicanálise e vínculo social. Rio de Janeiro: Jorge Zahar.

Enriquez, E. (1996). Prefácio. In R. Davel \& J. Vasconcelos (Orgs.), “Recursos humanos" e subjetividade. (pp. 7-22). Petrópolis: Vozes.

Enriquez, E. (2001). O papel do sujeito humano na dinâmica social. In J. N. A. Araújo, E. M. Castro, M. N. M. Machado \& S. Roedel (Orgs.), Psicossociologia: análise social e intervenção. (pp. 27-44). Belo Horizonte: Autêntica.

Enriquez, E. (2006). O homem do século XXI: sujeito autônomo ou indivíduo descartável. Rae - Revista de Administração de Empresas/Eletrônica, 5(10), 1-14.

Enriquez, E. \& Michel, J. B. (2005). Poder. In E. Enriquez, A. Lévy \& J. B. Michel (Orgs.), Dicionário de psicossociologia. (pp. 157-165). Lisboa: Climepsi.

Gaulejac, V. (2007). Gestão como doença social. São Paulo: Ideias \& Letras. 
Gaulejac, V. (2011). NGP: a nova gestão paradoxal. In P. Bendassolli, L. A. P. Soboll (Orgs.), Clinicas do trabalho: novas perspectivas para a compreensão do trabalho na atualidade. (pp. 84-98). São Paulo: Atlas.

Kind, L. (2004). Notas para o trabalho com a técnica de grupos focais. Psicologia em Revista, 10(15), 124-136.

Lhuilier, D. (2005). Trabalho. In E. Enriquez, A. Lévy \& J. B. Michel (Orgs.), Dicionário de psicossociologia. (pp. 210-219). Lisboa: Climepsi.

Lhuilier, D. (2017). O agir em psicossociologia do trabalho. Psicologia em Revista, 23(1), 295-311.

Ollivier, B. (2005). Autonomia. In E. Enriquez, A. Lévy \& J. B. Michel (Orgs.), Dicionário de psicossociologia. (pp. 24-32). Lisboa: Climepsi.

Rouchy, J. C. (2001). Identificação e grupos de pertencimento. In J. N. G. Araújo \& T. C. Carreteiro (Orgs.), Cenários sociais e abordagem clínica. (pp. 123-139). São Paulo: Escuta; Belo Horizonte: Fumec.

Rousseau, D. (1995). Psychological contract in organizations: understanding written and unwritten agreements. Thousand Oaks: Sage.

Schwartz, Y. (2011). Manifesto por um ergoengajamento. In P. Bendassolli, L. A. P. Soboll (Orgs.), Clinicas do trabalho: novas perspectivas para a compreensão do trabalho na atualidade. (pp. 132-166). São Paulo: Atlas. 